$\begin{array}{llll}\text { AL-Qadisiya Journal of Vet.Med.Sci. } & \text { Vol./12 } & \text { No./2 } & 2013\end{array}$

\title{
Compare between two methods for diagnosis of coccidia in broiler chicken
}

\author{
O. A. R. AlJumaili \\ Technical institute of Alanbar \\ e-mail:OD74AY@YAHOO.COM
}

\begin{abstract}
Coccidial infections in broiler cause significant economic losses because of decreased growth and feed utilization. To detect infection, gross evaluation of the intestinal tract and a microscopic evaluation of a wet smear are used as routine diagnostic methods. The aims of this study were to compare qualitative method (fecal floatation) with other methods of diagnosis ( wet smear). 14000 rose broiler breed between 26 and 42 days of age from 2 flocks in Fallujah city were evaluated. 40 fecal specimens were collected and examined by fecal floatation method for each flock. Wet smears, mucosal impressions were obtained from the middle jejunum, ileum, and cecum from each broiler. The result of floatation method give $(++)$ of oocysts in the all sample while the wet smear method give negative result in the same farm and same time. In concluded the floatation fastest and most accurate method for detection of coccidia
\end{abstract}

\section{Introduction}

Coccidiosis is a disease that is caused by protozoan parasites of the genus Eimeria, developing within the intestine of most domestic and wild animals and birds. Seven species of Eimeria (E. acervulina, E.brunetti, E. maxima, E. mitis, E. necatrix, E. praecox and E. tenella) are recognized as infecting chickens. Although coccidiosis is a disease known for many years, it is still considered as the most economical important parasitic condition affecting poultry production worldwide. Based on a compartmentalized model (1). Flocks infected as a result of mild to severe exposure usually shows a marked decrease in food and water consumption and birds become depressed and tend to huddle. Decreased weight gains occur as a result of the disruption of the intestinal mucosa where minimal absorption is taking place. Diarrhea may result as the host is trying to flush the organism from the body, which may induce dehydration. Lesions of the intestinal mucosa and loss of pigmentation may also become apparent during the latter stages of infection $(2,3,4,5)$. Diagnosis of coccidia may require careful consideration of the history' of the outbreak, symptoms, and autopsy findings, although usually the presence of the disease is conclusively demonstrated by the finding of coccidia in intestinal contents or droppings when these are subjected to microscopic examination. As indicated, next to the fact Eimeria are very effective parasites, one of the main reasons coccidiosis is still a major problem, is the difficult diagnosis. The classical parasitological methods of diagnosis are labor intensive and therefore costly. Oocyst per gram (OPG) counts in faeces or litter have a poor relation with the impact of the parasite on the performance of a flock. Identification of different species based on morphology of oocysts is very challenging and requires expertise. Lesion scoring is an interpretation based on macroscopic visible lesions caused by Eimeria, usually following a scoring system from zero to four (6). Various techniques have been developed for postmortem examination. Procedures basic to most techniques include (a) placing the bird on its back and severing the skin and fascia between the legs across the abdomen, (b) breaking the legs out of 
the acetabular articulation, (c) pulling the skin away from the musculature from the vent to the beak, (d) removing the breast, being careful not to damage internal organs

\section{Material and methods:}

14000 rose broiler breed between 26 and 42 days of age from 2 flocks in Fallujah city were evaluated. 40 fecal specimens were collected and examined by fecal floatation method for each flock naturally infected fecal floatation method For this purpose it is necessary to send 40 fresh droppings taken at random on farms on about day 26 of rearing and conserved in $2 \%$ potassium dichromate solution to the analytical laboratory for examination. Placed the samples in vials clean containing or to sever large vessels, and (e) exposing the abdominal cavity and viscera for examination (7).

$100 \mathrm{ml}$ of water in addition to the $2 \%$ dichromate potassium and keep at least third amount air. In the laboratory samples were filtered by using a fine sieve. Then take $3 \mathrm{ml}$ of filtered sample and add $6 \mathrm{ml}$ of saturated salt solution, filling the tube enough to form a positive meniscus before placing a $22 \times 22 \mathrm{~mm}$ coverslip on the lip of the tube orifice, then placed on the glass slide and examined under the microscope(8) fig(1) the oocytes were calculated as described in the table(1).

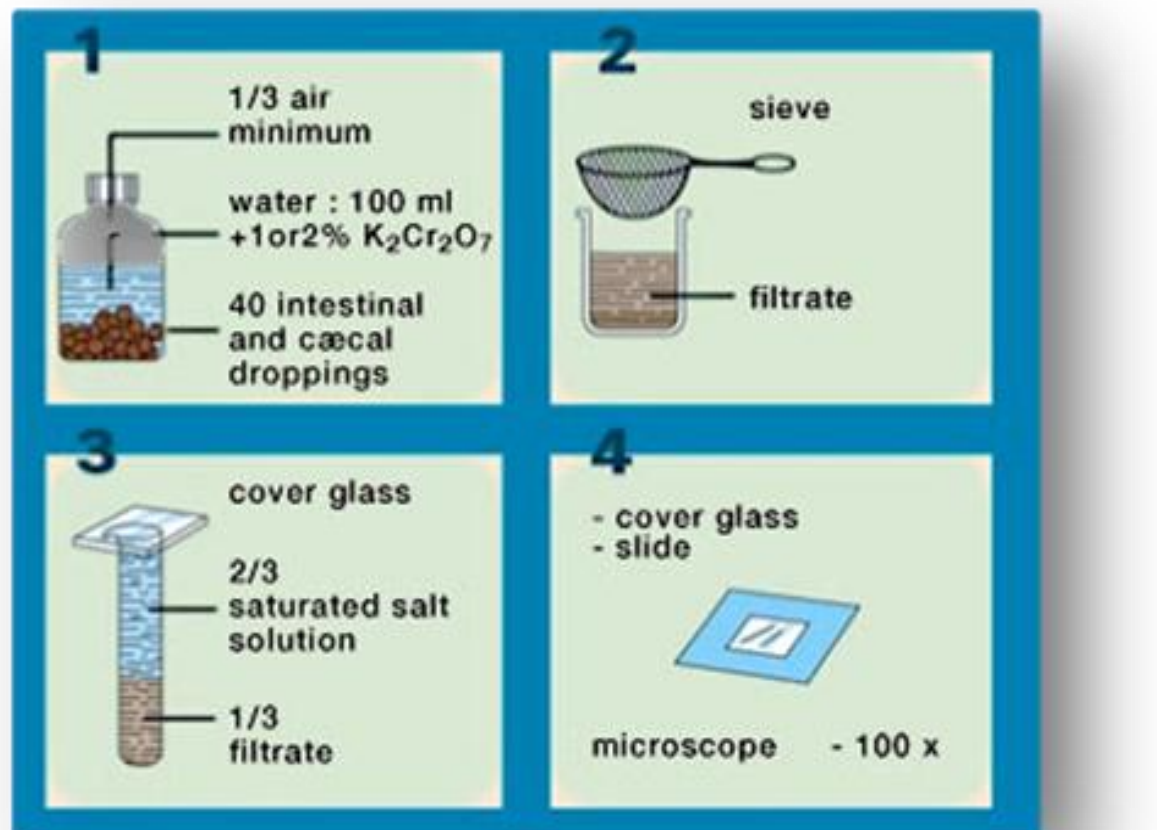

Fig (1): steps of fecal floatation method

\begin{tabular}{|l|l|}
\hline No. of positive & No. of oocysts \\
\hline 0 & No oocysts \\
\hline+ & Less than one oocyst/field \\
\hline++ & 1 to 10 oocysts/ field \\
\hline+++ & 10 to 20 oocysts/field \\
\hline++++ & More than 20 oocysts/field \\
\hline
\end{tabular}

table(1).method of calculating the oocytes as described in the. 
Wet smear method depend on microscopic examination of the scrapings of mucous membrane, should be made from five or more locations along the gut wall. Areas with lesion should be selected if present. If no suspicious areas are located, select from a) the duodenal area a centimeter or two below the entrance of the bile duct, b) the middle gut region which may be located by the yolk sac diverticulum, c) the lower intestinal area afew centimeters above the union with the cecal pouches, d) an area from near the middle of the cecum, and e) the rectal area" (9). It is possible to confirm or refute the presence of coccidia and may help with the identification of species when the site is taken into consideration. The result.The floatation method to detect coccidia presence of 1-10 oocytes in each microscopic field give ++ As shown in Table( 2) and pic $(1,2,3,4,5,6)$ The results of wet smear method for the same farm did not show any clear oocytes

\begin{tabular}{|l|c|c|}
\hline $\begin{array}{c}\text { No. of } \\
\text { sample }\end{array}$ & $\begin{array}{c}\text { Sample } \\
1\end{array}$ & $\begin{array}{c}\text { Sample } \\
2\end{array}$ \\
\hline method & & ++ \\
\hline Fecal floatation & ++ & nil \\
\hline Wet smear & nil & . \\
\hline
\end{tabular}

Table(2)Positive coccidial diagnosis in broiler flocks by different techniques. 


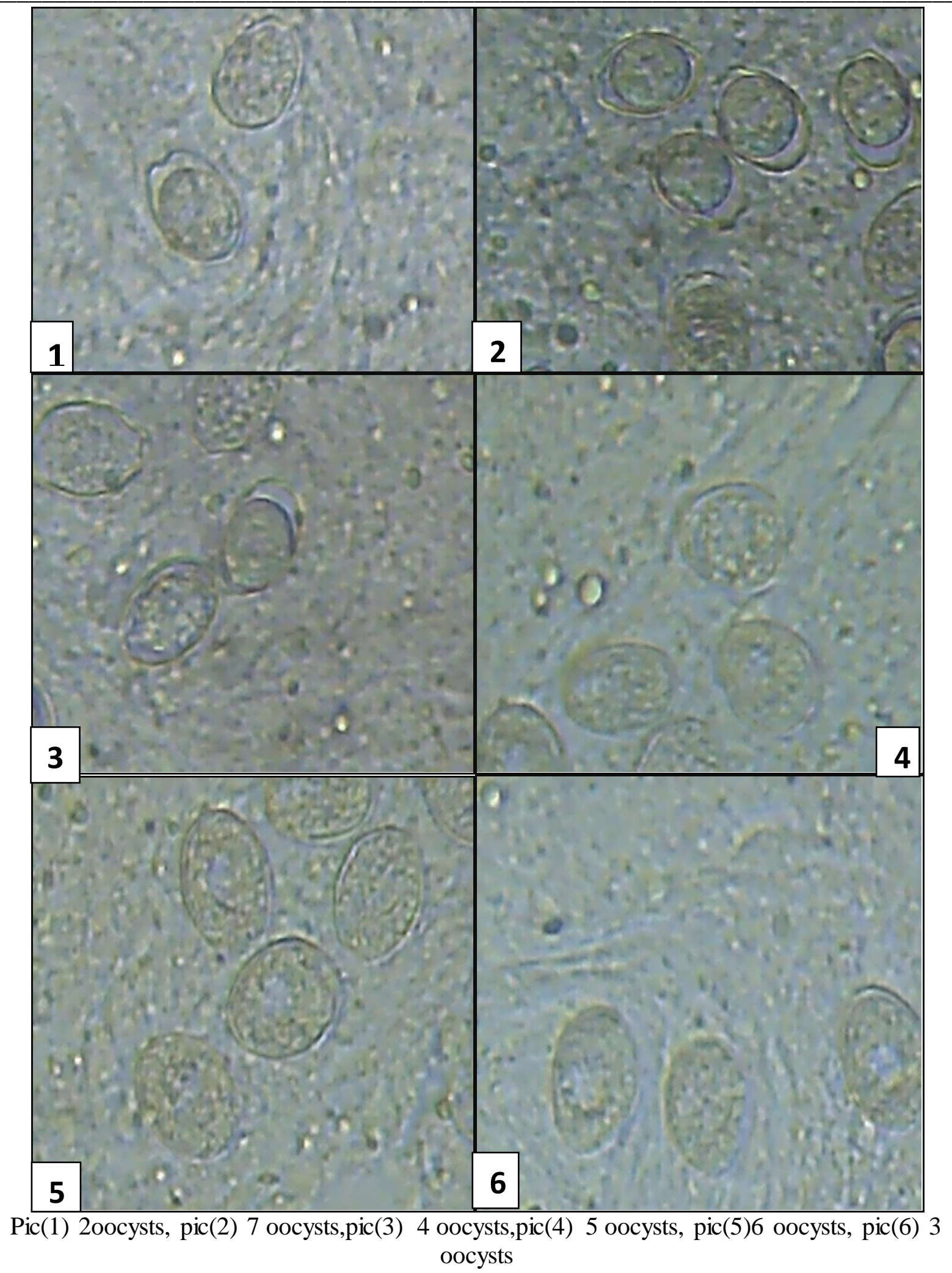




\section{Discussion}

Coccidiosis is an old and wellrecognized parasitic disease,and has significant economic impact on poultry production (10). In the poultry industry, several other bacterial/viral diseases get more importance because of sudden attack and high mortality. But, coccidiosis is a type of protozoal disease that causes maximum economic loss and has remained unattended, may be due to sub-clinical form of the disease (11). In this study, we find

\section{Reference}

1- WILLIAMS, R.B. (1999) A compartmentalised model for the estimation of the cost of coccidiosis to the world's chicken production industry. International Journal for Parasitology, 29(8):1209-1229.

2- Conway, D.P. and Mckenzie, M.E. (1991): Poultry coccidiosis diagnostic and testing procedures, 2nd Ed., chapter 2:17-36.

3- Edgar, S. A. (1992): Field diagnosis of coccidiosis in chickens. Agri-Bio Corporation.

4- Lillehoj, H. S. and Trout, J. M. (1993): Coccidia: A review of recent advances on immunity and vaccine development. Avian Pathol. 22:331.

5- McDougald, L.R. and Reid, W.M. (1997): Coccidiosis In: B.W.Calnek Disease of Poultry 10th edition by Mosby - Wolfe, Pp. 780-797.

6- JOHNSON, J. and REID, W.M. (1970) Anticoccidial drugs : lesion scoring techniques in battery and floor pen experiments with chickens. Experimental Parasitology 28: 30-36. that test result of fecal floating method was the fastest and possible to show oocytes before postmortem signs appear than the results of wet smear were all negative, the qualitative method( fecal floatation) concentrate oocysts for 40 sample in single slide compared to the second method. Advantages of qualitative method( fecal floatation) include: a) inexpensive, b) rapid, c) provides a permanent record, d)time and place to make diagnosis can be arranged

A

7- Zander, D. V., and E. T. Mallinson. 1991. Principles of disease prevention: diagnosis and control. In Disease of Poultry,9th ed., ed. B. W. Calnek, H. J. Barnes, C. W. Beard, W. M.Reid, and H.W. Yoder, Jr., 3-44. Ames, IA: Iowa State Univ.Press.

8- Conway D. and McKenzie M., 2007 Poultry Coccidiosis Diagnostic and Testing Procedures. 3rd Edn, 2121 state Avneu, Ames, lowa, USA.

9- Long, P. L., andW. M. Reid. 1982. A Guide for the Diagnosis of Coccidiosis in Chickens. Research Report 404 (Report355 revised). Athens, GA: College of Agriculture Experiment Station, Univ. Georgia.

10- Allen, P.C. and Fetterer R.H. (2002) Recent advances in biology and immunobiology of Eimeria species and in diagnosis and control of infection with these coccidian parasites of poultry, Clinical Microbiology Review, 15: 58-65.

11- Vermeulen, A.N., Schaap D.C. and Schetters, T.P.M. (2001) Control of coccidiosis in chickens by vaccination, Veterinary Parasitology, 100: 13-20. 